\title{
Preservative-Free Tafluprost $0.0015 \%$ in the Treatment of Patients with Glaucoma and Ocular Hypertension
}

\author{
Carl Erb · Ines Lanzl · Seid-Fatima Seidova · Friedemann Kimmich
}

Received: February 15, 2011 / Published online: June 30, 2011

(c) The Author(s) 2011. This article is published with open access at Springerlink.com

\section{ABSTRACT}

Introduction: The objective of this study was to evaluate efficacy, local tolerability, and safety of this first-in-class preservative-free prostaglandin preparation in patients with ocular hypertension and glaucoma. Methods: Patients with glaucoma or ocular hypertension who required a change of medication or were naïve to treatment were included in this noninterventional and observational study. Noninterventional means that no influence was made upon the decision of the physicians to include specific patients and upon the treatment algorithm used. German law for observational studies does not allow any influence on the choice of drugs used, patient

Carl Erb

Klinik am Wittenbergplatz, Kleiststr. 23-26, D-10787

Berlin, Germany

Ines Lanzl · Seid-Fatima Seidova

Private Practice, Geigelsteinstr. 26, D-83209 Prien,

Germany

Friedemann Kimmich $(\bowtie)$

eyecons, Woeschbacherstr. 37, D-76327 Pfinztal,

Germany. Email: F.Kimmich@eyecons.de selection, masking, and comparator treatment regimens. The main aim of this observational study was to collect "real-life data" on the efficacy and safety of a new medical treatment after approval in a large patient population. Participating ophthalmologists were asked to provide anonymous patient data collected during regular visits by filling a simple data entry form. Intraocular pressure (IOP) readings were recorded at baseline (previous therapy or untreated) and 6-12 weeks after changing medical treatment to or initiating treatment with preservative-free tafluprost once daily. Changes in the IOP were evaluated over the study period for all patients as well as for specific pretreatment subgroups. Local comfort was determined using a five-point scale (very good, good, satisfactory, less satisfactory, not acceptable) before and after the change of medical treatment. All adverse events were recorded. Results: Data from 2123 patients with glaucoma or ocular hypertension were considered for the final evaluation. Medication was changed in $41.1 \%$ of patients due to tolerability issues and in $25.6 \%$ of patients due to insufficient efficacy with prior medication. In all patients preservative-free tafluprost $0.0015 \%$ lowered 
IOP from $19.5 \pm 4.4 \mathrm{mmHg}$ (baseline) to $16.4 \pm 2.9 \mathrm{mmHg}$ after $6-12$ weeks. Preservativefree tafluprost also significantly lowered the IOP in all monotherapy subgroups: treatment-naïve patients $(n=440): 22.6 \pm 3.9$ $\mathrm{mmHg}$ (baseline) to $16.7 \pm 2.7 \mathrm{mmHg}$ (week 6-12); beta blockers $(n=307): 20.3 \pm 3.5 \mathrm{mmHg}$ (baseline) to $16.7 \pm 2.6 \mathrm{mmHg}$ (week 6-12); carbonic anhydrase inhibitors $(n=158)$ : $19.0 \pm 3.6 \mathrm{mmHg}$ (baseline) to $16.0 \pm 2.6 \mathrm{mmHg}$ (week 6-12); prostaglandin analogs (PGAs; $n=447$ ): $16.8 \pm 2.9 \mathrm{mmHg}$ (baseline) to $15.8 \pm 2.6$ $\mathrm{mmHg}$ (week 6-12). Local comfort was rated as "very good" or "good" by $85.6 \%$ of patients at the final visit $(P<0.001)$. Only few adverse events occurred during the treatment period: 18 patients $(0.8 \%)$ discontinued medical treatment with preservative-free tafluprost due to local intolerance; six patients $(0.3 \%)$ due to efficacy issues; four patients complained about systemic side effects $(0.2 \%)$; and two patients preferred to use a multidose treatment regimen (0.2\%). Conclusion: Although this study was limited by its observational design the results demonstrate that preservative-free tafluprost $0.0015 \%$ was effective, generally well tolerated, and safe in a broad and heterogeneous patient population.

Keywords: glaucoma; ocular hypertension; ocular surface disease; preservatives; prostaglandin analogs; tafluprost

\section{INTRODUCTION}

Glaucoma is the second leading cause of blindness worldwide: an estimated 60.5 million people will have glaucoma by 2010 , increasing to 79.6 million by $2020 .{ }^{1}$ The disease is characterized by a progressive loss of retinal ganglion cells leading to optic nerve atrophy and visual field defects. The etiology of glaucoma is probably multifactorial, however, increased intraocular pressure (IOP) is considered to be the most important risk factor and, thus far, is the only risk factor that can be modified. ${ }^{2}$ Major outcome studies have shown that lowering IOP is beneficial for patients with primary open-angle glaucoma, normal-tension glaucoma, and ocular hypertension. ${ }^{2-6}$ Worldwide, prostaglandins have become the major therapeutic class for medical treatment of glaucoma because of their excellent efficacy and favorable safety profile. ${ }^{7}$ Tafluprost is a novel prostaglandin that has been approved for ophthalmic use in a number of markets worldwide. Tafluprost is highly selective for the prostaglandin FP-receptor. ${ }^{8}$ The drug is the first and only prostaglandin that is available in a preservative-free formulation for the treatment of patients with glaucoma and ocular hypertension. In controlled clinical studies the drug lowered IOP effectively and was generally well tolerated. ${ }^{9-11}$

Numerous experimental and clinical studies clearly demonstrate that the long-term use of preserved topical drugs may induce side effects at the ocular surface. The most frequently used preservative, benzalkonium chloride (BAC), has consistently been shown to induce toxic effects in laboratory, experimental, and clinical studies. BAC is proapoptotic, proinflammatory and causes tear film instability and loss of goblet cells. ${ }^{12-15}$ These changes cause irritation, ocular discomfort, and subjective visual complaints. Furthermore, more severe side effects, such as chronic inflammation or a progressive development of fibrosis, may increase the risk of failure after glaucoma filtering surgery. ${ }^{16,17}$ Therefore, preservativefree medications may be beneficial for many glaucoma patients.

The purpose of the present study was to evaluate the efficacy, local tolerability, and safety of preservative-free tafluprost $0.0015 \%$ 
in a naturalistic setting using a prospective, observational design.

\section{MATERIALS AND METHODS}

\section{Study Design}

This study was a prospective, multicenter, noninterventional, observational, open-label study conducted in Germany between July 2009 and February 2010. Patients with glaucoma or ocular hypertension who the investigators determined to require a change of medication, an add-on therapy, or who were treatment naïve were followed for 6-12 weeks after they were switched to once-daily therapy with preservative-free tafluprost $0.0015 \%$ (Taflotan $^{\circledR}$, Taflotan ${ }^{\circledR}$ sine, Tapros ${ }^{\circledR}$, Santen Pharmaceutical Co., Ltd., Osaka, Japan, Saflutan ${ }^{\circledR}$ Merck \& Co. Inc., USA) or after initiation of medical treatment (treatment-naïve patients). Six hundred and sixty-one participating ophthalmologists provided anonymous patient data using a standardized data-collection instrument.

The study treatment was based only on the decision of the physician and their reasons for prescribing the new medication were collected. German law does not require informed consent for this type of noninterventional observational studies. At baseline demographics, diagnoses and information about prior treatments were collected and IOP readings and tolerability measures were recorded. IOP measurements were made for each eye at baseline (on prior treatment or without treatment in treatmentnaïve patients), and at final visit between 6 to 12 weeks after switching to or initiation of medical therapy with preservative-free tafluprost $0.0015 \%$ using Goldman applanation tonometry. Tolerability was determined using a five-point scale (very good, good, satisfactory, less satisfactory, not acceptable). For the evaluation of local tolerability the investigator asked the patients to rate the local comfort using this five-point scale. Patients' and physicians' satisfaction with preservative-free tafluprost were recorded at the final visit using a four-point scale (very satisfied, satisfied, less satisfied, not satisfied at all). For the evaluation of the overall satisfaction the investigator asked the patients to rate their degree of satisfaction on the fourpoint scale.

In total, datasets from 3350 patients were collected during the study period. Paired t-tests were conducted to compare IOP values at baseline with IOP values after treatment with tafluprost $0.0015 \%$. Bowker's test of symmetry was used for statistical comparison of local tolerability at final visit versus baseline. All adverse events were recorded by the physician by asking the patient whether any unexpected events occurred after changing or initiation of medication.

\section{RESULTS}

\section{Patient and Baseline Characteristics}

In total, 1227 patients were excluded from the evaluation. These included patients for whom the time-period between the two visits was $<4$ or $>12$ weeks $(n=808)$, patients with retrospectively collected data $(n=349)$, patients with datasets with incomplete IOP readings $(n=41)$, patients already treated at baseline with preservative-free tafluprost $(n=17)$, and patients with different medical treatment for the right and left eye and with data that were not plausible $(n=12)$. After the exclusion of these patients, 2123 patients of the initial dataset collected were eligible for the final evaluation. As shown in Table 1, the majority of the patients was female and suffered from primary open angle glaucoma. Poor local tolerance was the most common reported reason 
for changing medication to preservative-free tafluprost (41.1\%), followed by a lack of efficacy of the prior treatments (25.6\%; Figure 1).

Table 1. Characteristics of the patient population $(n=2123)$ included in the observational study with preservative-free tafluprost $0.0015 \%$.

\begin{tabular}{lll}
\hline Patient characteristics & & \\
\hline Mean age (range) & $65.5(16-97)$ & \\
\cline { 2 - 3 } SD & 12.1 & \\
n.d. & $n$ & \\
\hline Gender & $n$ & \\
Male & 808 & 38.1 \\
Female & 1300 & 61.2 \\
n.d. & 15 & 0.7 \\
\hline Diagnoses & & \\
Ocular hypertension & 190 & 8.9 \\
Primary open angle glaucoma & 1517 & 71.5 \\
Normal tension glaucoma & 194 & 9.1 \\
Pseudo exfoliation glaucoma & 112 & 5.3 \\
Other glaucomas & 46 & 2.2 \\
Pigment dispersion glaucoma & 17 & 0.8 \\
Narrow angle glaucoma & 14 & 0.7 \\
Multiple glaucomas & 23 & 1.1 \\
n.d. & 10 & 0.5 \\
\hline n.d.=no data. & &
\end{tabular}

In patients reporting a local intolerance at baseline, irritation was the most frequent symptom (36.6\%) followed by hyperemia (27.3\%), allergy (17.3\%), and itching (16.8\%; Figure 2).

\section{Prior Glaucoma Medication}

Prior to change of medication, patients used a variety of other glaucoma products $(n=1673$; $78.8 \%)$ or were naïve to treatment $(n=450$; $21.2 \%)$. The majority of patients were treated with a monotherapy $(n=1133 ; 53.4 \%)$, most frequently with a prostaglandin analog (PGA; $n=453 ; 21.3 \%)$ or a beta blocker $(n=372 ; 17.5 \%)$. Five-hundred and forty patients (25.4\%) were treated with fixed- or nonfixed combinations (Table 2).

\section{Effect on IOP}

In the overall patient population, IOP was significantly reduced from $19.5 \pm 4.4 \mathrm{mmHg}$

Figure 1. Reasons for changing therapy to preservative-free tafluprost $0.0015 \%$, adding preservative-free tafluprost $0.0015 \%$ to an existing medical treatment regimen, or initiating therapy with preservative-free tafluprost $0.0015 \%$. ${ }^{*}$ Multiple entries.

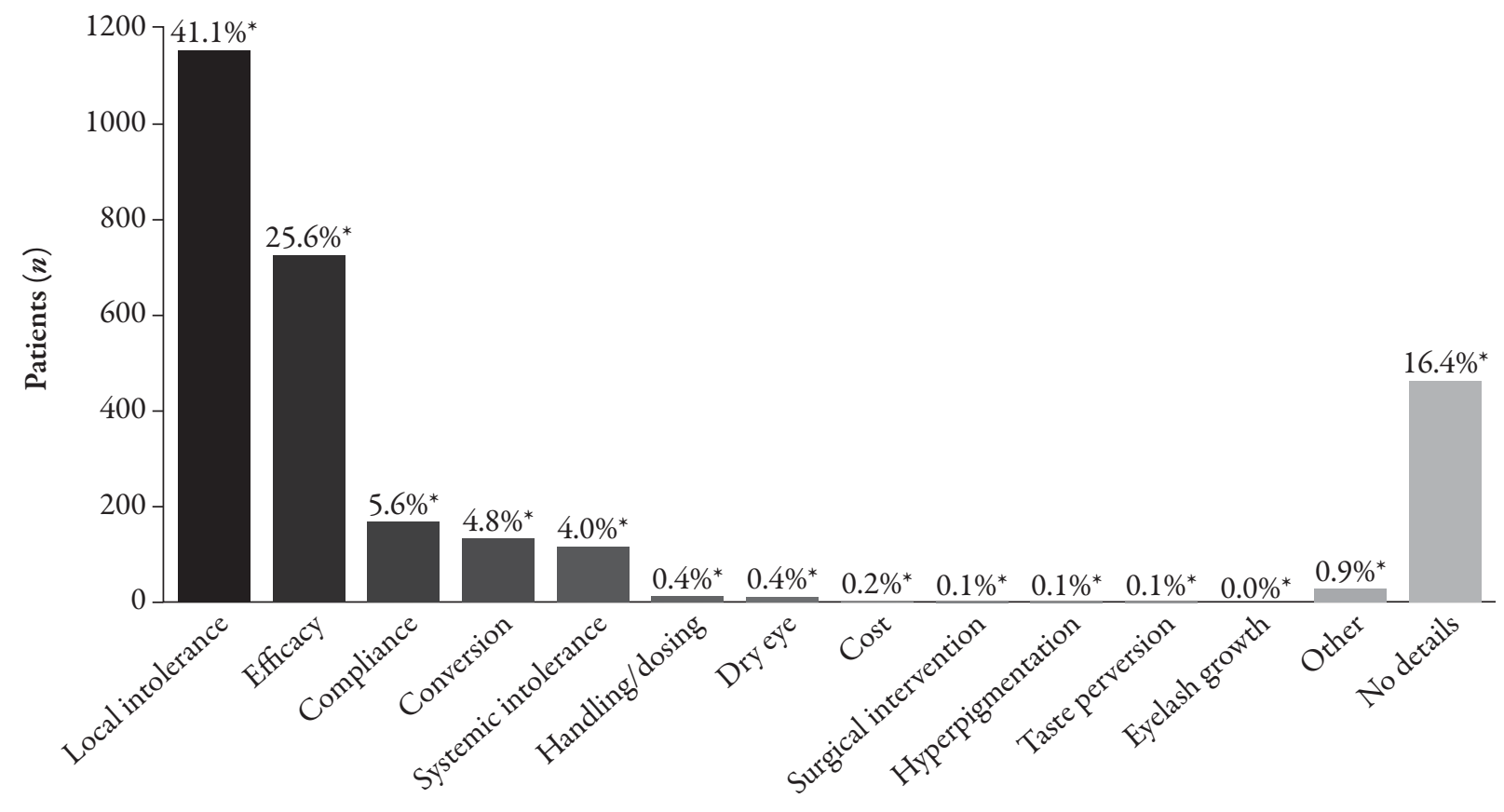


Figure 2. Local intolerances of prior medication at baseline stratified by type. Percentages refer to all patients $(n=2123)$. Multiple entries were possible. ${ }^{*}$ Multiple entries.



Table 2. Prior therapy used before initiating, switching, or adding preservative-free tafluprost $0.0015 \%$.

\begin{tabular}{lll}
\hline Prior treatment (type) & $n$ & $\%$ \\
\hline Treatment-naïe patients & 450 & 21.2 \\
Monotherapy & 1133 & 53.4 \\
Beta blockers & 372 & 17.5 \\
Prostaglandins & 453 & 21.3 \\
Alpha-2-adrenergic & 111 & 5.2 \\
receptor agonists & & \\
CAIs & 187 & 8.8 \\
Miotics & 10 & 0.5 \\
Combination therapy & 540 & 25.4 \\
Fixed combinations & 307 & 14.5 \\
Nonfixed combinations & 104 & 4.9 \\
ingredients) & & \\
Nonfixed combinations & 129 & 6.1 \\
( $\geq 3$ ingredients) & & 100.0 \\
Total & 2123 & \\
\hline CAI carbonic anhydrase inhibitor
\end{tabular}

$\mathrm{CAI}=$ carbonic anhydrase inhibitor.

at baseline to $16.4 \pm 2.9 \mathrm{mmHg}(P<0.001)$ with preservative-free tafluprost therapy at the final visit (Figure 3). Among all patients, ( $n=2123) 79.4 \%$ of eyes achieved an IOP level of $\leq 18 \mathrm{mmHg}, 50.9 \%$ of $\leq 16 \mathrm{mmHg}$, and $24.4 \%$ of $\leq 14 \mathrm{mmHg}$ (Figure 4). Overall the IOP was lower at the final visit compared with the baseline visit in 3224 eyes (76.6\%), equal in 467 eyes (11.1\%), and higher in 519 eyes (12.3\%; Figure $5)$. The mean IOP was reduced in treatmentnaïve patients and in all patient subgroups with prior monotherapy that were switched to monotherapy with preservative-free tafluprost. At the final visit, 6-12 weeks after initiating medical therapy with preservative-free tafluprost or after changing medication to a monotherapy with preservative-free tafluprost, the mean IOP values were significantly lower than at baseline $(P<0.001)$. Preservative-free tafluprost also lowered IOP significantly in all monotherapysubgroups: treatment-naïve patients $(n=440)$ : 22.6 $\pm 3.9 \mathrm{mmHg}$ (baseline) to $16.7 \pm 2.7 \mathrm{mmHg}$ (week 6-12); beta blockers ( $n=307$ ): $20.3 \pm 3.5$ $\mathrm{mmHg}$ (baseline) to $16.7 \pm 2.6 \mathrm{mmHg}$ (week 6-12); carbonic anhydrase inhibitors (CAIs) $(n=158): 19.0 \pm 3.6 \mathrm{mmHg}$ (baseline) to $16.0 \pm 2.6$ mmHg (week 6-12); PGAs ( $n=447)$ : $16.8 \pm 2.9$ $\mathrm{mmHg}$ (baseline) to $15.8 \pm 2.6 \mathrm{mmHg}$ (week 6-12). In Figure 6, the mean IOP \pm SD is shown for treatment-naïve patients and the subgroups of patients who had been previously treated with beta-blocker monotherapy, alpha-2adrenergic receptor agonist monotherapy, CAI monotherapy, and PGA monotherapy and were switched to a monotherapy with preservativefree tafluprost.

In treatment-naïve patients, the mean IOP at the final visit was lowered by -5.9 $\mathrm{mmHg}$, in patients with prior beta-blocker monotherapy by $-3.6 \mathrm{mmHg}$, in patients with prior alpha-2-adrenergic receptor monotherapy by $-3.1 \mathrm{mmHg}$, in patients with prior CAI monotherapy by $-3.0 \mathrm{mmHg}$, and in patients with a PGA monotherapy by -1.0 $\mathrm{mmHg}$. Preservative-free tafluprost was also used adjunctively to an existing monotherapy treatment regimen. In all subgroups of patients 
Figure 3. Mean intraocular pressure (IOP) \pm SD for all patients. ${ }^{*} P<0.001$ vs. corresponding baseline, paired t-test (last observation carry forward [LOCF] analysis).

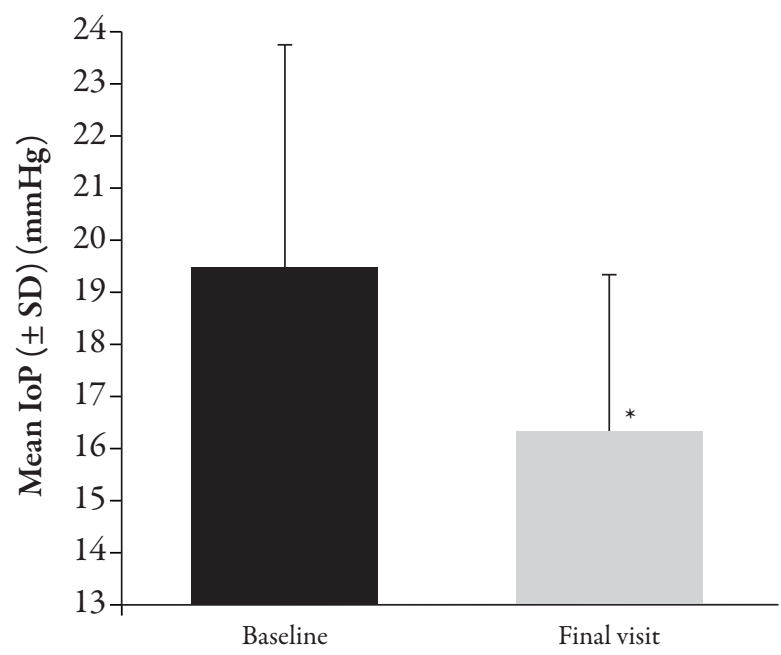

Figure 4. Intraocular pressure (IOP) levels at final visit 6-12 weeks after changing or initiation of medical therapy with tafluprost $0.0015 \%$.

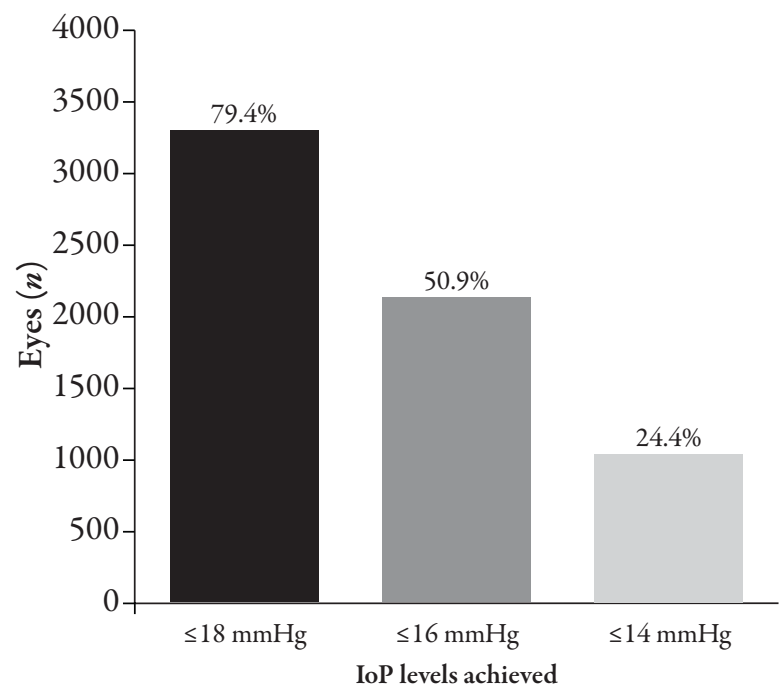

when preservative-free tafluprost was added to an existing monotherapy, the IOP was further reduced at the final visit. When given adjunctively to a prior monotherapy treatment regimen preservative-free tafluprost provided an additional IOP lowering effect: in patients with prior beta-blocker treatment the mean
Figure 5. Comparison of intraocular pressure (IOP) of individual patients/eyes at baseline vs. final visit.



IOP decreased by $-4.5 \mathrm{mmHg}$, in patients with prior CAI monotherapy by $-3.8 \mathrm{mmHg}$, and in patients with prior alpha-2-adrenergic receptor monotherapy by $-3.9 \mathrm{mmHg}$ (Figure 7).

\section{Local Tolerability and Patient Satisfaction}

Tolerability improved in the majority of patients after medication was changed to preservative-free tafluprost. At baseline, tolerability of the prior treatment was rated as "very good" and "good" by only $28.3 \%$ of the patients; $38.4 \%$ of patients rated the tolerability as "less satisfactory", and $18 \%$ as "not acceptable." Tolerability improved after the change of medication to preservativefree tafluprost; a total of $85.7 \%$ of patients rated the tolerability as "very good" and "good" (Figure 8). Specifically in patients treated with prior PGA monotherapy improvement of local tolerability was evident: at baseline only $1.3 \%$ and $8.3 \%$ of patients rated the local tolerability of their prior PGA treatment regimen with "very good" or "good" respectively. After the change of medication in these patient subgroups to preservative-free tafluprost, local tolerability 
Figure 6. Mean intraocular pressure $(\mathrm{IOP})( \pm \mathrm{SD})$ for the different monotherapy subgroups. ${ }^{*} P<0.001$.

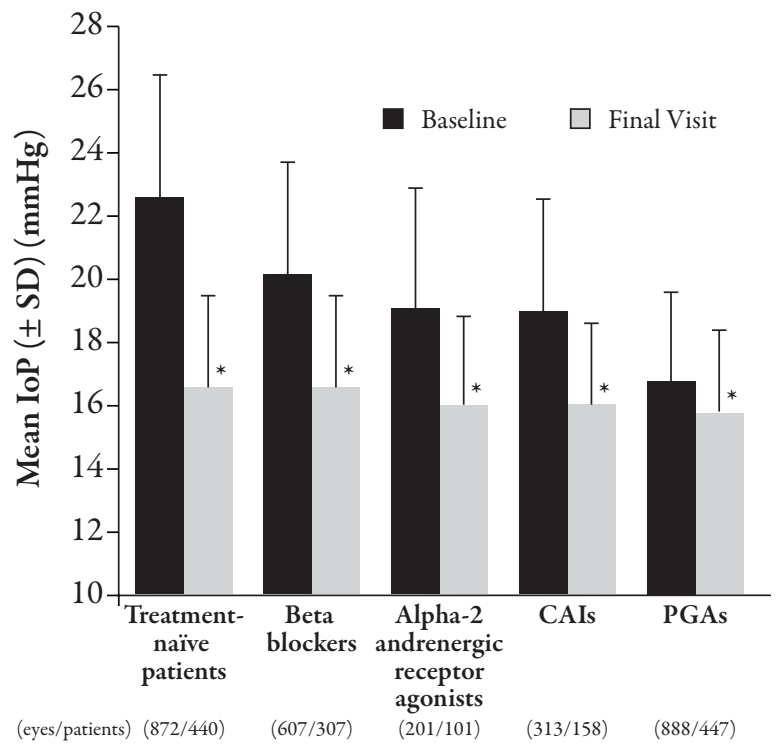

Figure 7. Mean intraocular pressure (IOP) for subgroups of patients when preservative-free tafluprost was given adjunctively to an existing monotherapy treatment regimen.

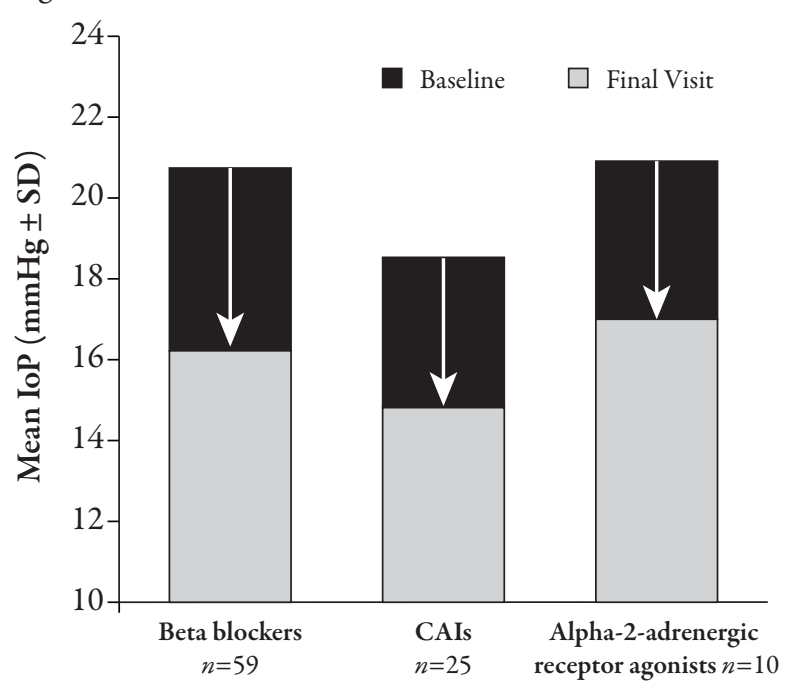

improved: local tolerability was rated as "very good" and "good" by 39.6\% and 46.3\% of patients, respectively (Figure 9). As shown in Figure 10, at the final visit most patients (92.9\%) and physicians (92.6\%) were very satisfied or satisfied with using preservative-free tafluprost.
Figure 8. Tolerability rating at baseline (prior medication) and at final visit (preservative-free tafluprost). $n=1741$ patients with ratings at baseline and at final visit.

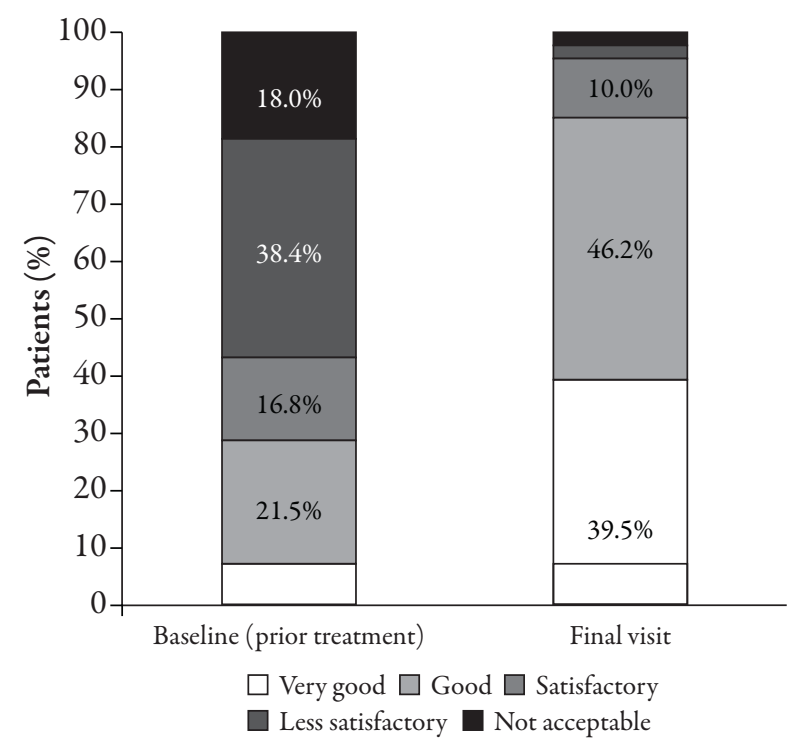

Figure 9. Tolerability rating at baseline (prior PGA monotherapy) and at final visit (preservative-free tafluprost). $n=447$ patients.



\section{Adverse Events and Discontinuations}

Only a few adverse events occurred during the treatment period. Therapy with preservativefree tafluprost was continued after the final visit by 2077 patients (97.8\%). Eighteen 
Figure 10. Satisfaction of patients and physicians with preservative-free tafluprost at final visit. $n=2123$.

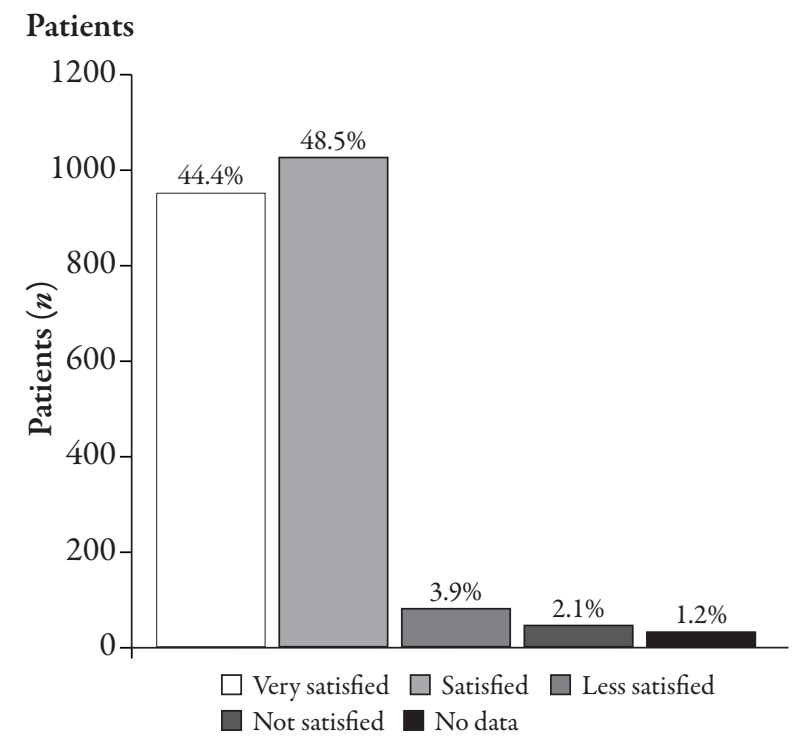

patients $(0.8 \%)$ discontinued medical treatment with preservative-free tafluprost due to local intolerance, six patients $(0.3 \%)$ due to efficacy issues, four patients complained about systemic side effects $(0.2 \%)$, and two patients preferred to use a multidose treatment regimen (0.2\%). Details are given in Table 3.

\section{DISCUSSION}

In the patient population of this noninterventional, open-label, multicenter observational study, medication was changed for two main reasons: first, many patients were switched to preservative-free tafluprost because of tolerability issues with their prior medication. Local intolerance accounted for $41.1 \%$ of changes of treatment in all patients. Second, medical treatment was changed because of lack of efficacy of prior medication in $25.6 \%$ of all patients. Irritation (36.6\%), hyperemia (27.3\%), allergy (17.3\%), and/or stinging (16.8\%) were the most common symptoms at baseline before changing medical therapy. The results demonstrate that preservative-free tafluprost can

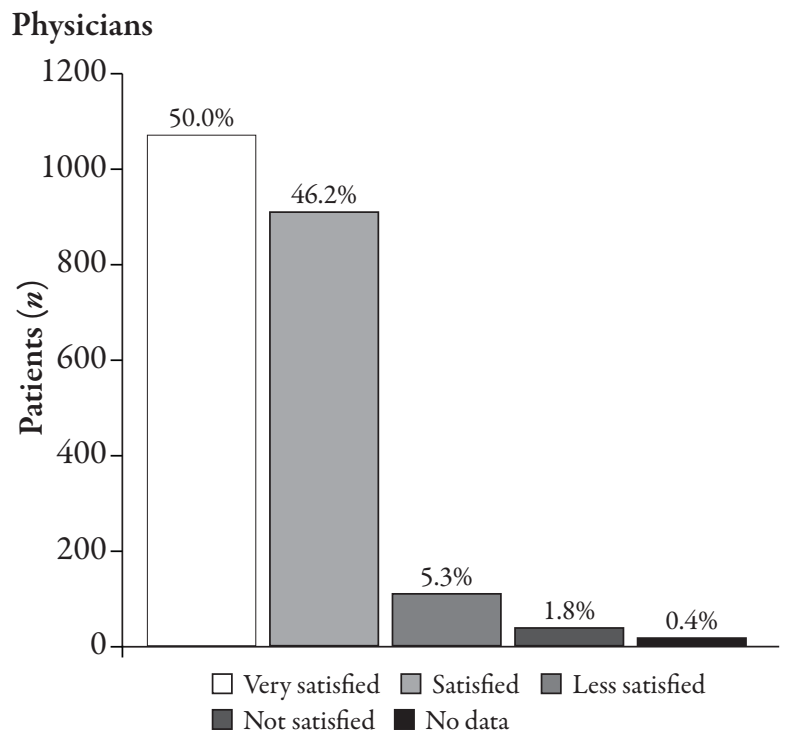

Table 3. Discontinuations until and after the final visit.

\begin{tabular}{lll}
\hline $\begin{array}{l}\text { Reasons for termination of medical } \\
\text { treatment }\end{array}$ & $n$ & $\%$ \\
\hline Allergy & 2 & 0.1 \\
Compliance & 1 & 0.0 \\
Efficacy & 6 & 0.3 \\
Handling & 2 & 0.1 \\
Local and systemic intolerance & 1 & 0.0 \\
Local intolerance & 14 & 0.7 \\
Local intolerance and allergy & 1 & 0.0 \\
Not medication related & 1 & 0.0 \\
Patient preference & 6 & 0.3 \\
Surgery & 4 & 0.2 \\
Systemic intolerance & 4 & 0.2 \\
Unknown & 2 & 0.1 \\
\hline Total terminations & 46 & 2.2 \\
Therapy continued & 2077 & 97.8 \\
\hline
\end{tabular}

achieve good IOP control in this difficult patient population. The mean IOP in this patient cohort at baseline was relatively low, $19.5 \pm 4.4 \mathrm{mmHg}$. This may be explained by the relatively high number of patients who were treated either with a PGA monotherapy $(n=453 ; 21.3 \%)$ or a fixed or nonfixed combination $(n=540 ; 25.4 \%)$ at 
baseline before changing medication. Regardless of the low mean baseline IOP, lower IOP values were achieved 6-12 weeks after changing medication in more than three-quarters of all eyes ( $n=3224$ eyes, $76.6 \%$ ). The IOP remained at the same level in 467 eyes (11.1\%), and was higher in 519 eyes (12.3\%) of all eyes.

There are several explanations for the higher IOP at the final visit compared with the baseline visit: first, even a relatively small increase of $1 \mathrm{mmHg}$ compared with treated low baseline IOPs is counted as an increase. Second, patients with prior fixed combinations that were switched to a monotherapy with preservativefree tafluprost in order to reduce possible side effects were included in this analysis. Finally, patients whose IOPs were well-controlled by their prior PGA monotherapy who were switched to preservative-free tafluprost due to tolerability issues may also explain this finding. In $79.4 \%$ of all eyes IOP values of $\leq 18 \mathrm{mmHg}$ were achieved at the final visit, IOP values of $\leq 16 \mathrm{mmHg}$ were achieved in more than half of the eyes (50.9\%), and IOP values of $\leq 14 \mathrm{mmHg}$ were achieved in slightly less than a quarter of all eyes (24.4\%). The change of medical treatment in patients treated with a prior monotherapy to preservative-free tafluprost provided a significant additional reduction in the mean IOP. Furthermore, when given adjunctively to an existing monotherapy with beta blockers, CAIs, or alpha-2-adrenergic receptor agonists, preservative-free tafluprost provided an additional decrease in the mean IOP. At the final visit, local tolerability increased compared with baseline. This was especially evident in the patient subgroup using preserved prostaglandins at baseline. Consequently, a high number of patients and physicians rated their satisfaction with preservative-free tafluprost at the final visit as "very satisfactory" or "satisfactory".
Clinical studies show that a high proportion of glaucoma patients that were treated with preserved glaucoma medications developed symptoms such as burning and stinging, foreign-body sensation, dry eye, and other symptoms consistent with ocular surface irritation. ${ }^{17-21}$ As shown in previous studies, the present results confirm that patients with irritation of the ocular surface, subjective symptoms, and clinical signs, such as hyperemia, may benefit from a change of medication to preservative-free tafluprost. ${ }^{22,23}$ Many experimental and clinical studies have clearly demonstrated that the long-term use of topical drugs containing preservatives may induce changes in the ocular surface, tear film instability, epithelial apoptosis, conjunctival inflammation, and the loss of goblet cells. ${ }^{18,24,25}$ After switching to preservative-free tafluprost, local tolerability improved in most patients, and the overall patient satisfaction with their glaucoma treatment increased. The present study did not reveal any causal relationship between the preservative-free nature of tafluprost and the improvement in tolerability. Beside the preservative-free nature of the drug, the low concentration of tafluprost itself may contribute to the improvement of local tolerability and patient satisfaction seen in this observational study.

The present study had both strengths and limitations. The observational design may better reflect the actual clinical practice compared with controlled clinical trials. Due to its observational nature, the study did not reveal any causal relationships. The observed reduction in IOP after switching might be ascribed to the improvement of subjective symptoms and clinical signs, and thus, a better compliance. However, regression to the mean cannot be ruled out in the present study design as a control group was not used. 
It can be assumed that this patient population is representative of patients who are likely to be prescribed a preservative-free glaucoma medication. However, further studies with higher numbers of patients in the different subgroups are necessary to determine what aspects of preservative-free therapy with tafluprost account for the observed treatment effects.

\section{CONCLUSION}

Preservative-free tafluprost $0.0015 \%$ was effective, well tolerated, and associated with fewer adverse events compared with baseline medications. A change of medical therapy to preservative-free tafluprost may be beneficial, especially for patients with subjective ocular symptoms and patients with sensitive or dry eyes but also for patients who are not responding adequately to other monotherapy treatment regimens. A further reduction in the IOP was achieved in patients who were switched from other monotherapies, including betablockers, CAIs, and PGAs to monotherapy with preservative-free tafluprost.

\section{ACKNOWLEDGMENTS}

This study was financially supported by Santen Oy, Tampere, Finland. C.E. and I.L are speakers for Santen Oy. SF.S has no financial or other significant relationships to Santen Oy. F.K is a consultant to Santen Oy.

Medical writing, data management, and statistical analysis of the present study were undertaken by eyecons (F.K.) with financial support by Santen Oy. The authors have no proprietary interests in Santen Oy or in the therapy product. F.K. is the guarantor for this article, and takes responsibility for the integrity of the work as a whole.
Previous presentations: Preliminary reports of these data were presented at: XXXIX Nordic Congress of Ophthalmology, Reykjavík, Iceland, August 4-7, 2010; 9th Congress of the European Glaucoma Society (EGS), Madrid, Spain, September 12-17, 2010; EVER 2010 Congress, Creta, Greece, October 6-9, 2010; and at the 114th Annual Meeting of the American Academy of Ophthalmology (AAO), Chicago, October 16-19, 2010.

Open Access. This article is distributed under the terms of the Creative Commons Attribution Noncommercial License which permits any noncommercial use, distribution, and reproduction in any medium, provided the original authors and source are credited.

\section{REFERENCES}

1. Quigley HA, Broman AT. The number of people with glaucoma worldwide in 2010 and 2020. Br J Ophthalmol. 2006;90:262-267.

2. Leske MC, Heijl A, Hussein M, et al. Factors for glaucoma progression and the effect of treatment: the Early Manifest Glaucoma Treatment Trial. Arch Ophthalmol. 2003;121:48-56.

3. AGIS Investigators. The Advanced Glaucoma Intervention Study (AGIS): 7. The relationship between control of intraocular pressure and visual field deterioration. Am J Ophthalmol. 2000;130:429-440.

4. Heijl, A, Leske, MC, Bengtsson, B, et al. Reduction of intraocular pressure and glaucoma progression: results from the Early Manifest Glaucoma Trial. Arch Ophthalmol. 2002;120:1268-1279.

5. Collaborative Normal-Tension Glaucoma Study Group. Comparison of glaucomatous progression between untreated patients with normal-tension glaucoma and patients with therapeutically reduced intraocular pressures. Am J Ophthalmol. 1998;126:487-497.

6. Kass, MA, Heuer, DK, Higginbotham, EJ, et al. The Ocular Hypertension Treatment Study: a randomized trial determines that topical ocular 
hypotensive medication delays or prevents the onset of primary open-angle glaucoma. Arch Ophthalmol. 2002;120:701-713.

7. Bean GW, Camras CB. Commercially available prostaglandin analogs for the reduction of intraocular pressure: similarities and differences. Surv Ophthalmol. 2008; 53(Suppl. 1):S69-S84.

8. Takagi Y, Nakajima T, Shimazaki A, et al. Pharmacological characteristics of AFP-168 (tafluprost), a new prostanoid FP receptor agonist, as an ocular hypotensive drug. Exp. Eye Res. 2004;78:767-776.

9. Traverso CE, Ropo A, Papadia M, et al. A phase II study on the duration and stability of the intraocular pressure-lowering effect and tolerability of tafluprost compared with latanoprost. J Ocul Pharmacol Ther. 2010;26:97-104.

10. Hamacher T, Airaksinen J, Saarela V, Liinamaa MJ, Richter U, Ropo A. Efficacy and safety levels of preserved and preservative-free tafluprost are equivalent in patients with glaucoma or ocular hypertension: results from a pharmacodynamics analysis. Acta Ophthalmol Suppl (Oxf). 2008;242:14-19.

11. Uusitalo H, Pillunat LE, Ropo A, et al. Efficacy and safety of tafluprost $0.0015 \%$ versus latanoprost $0.005 \%$ eye drops in open-angle glaucoma and ocular hypertension: 24-month results of a randomized, double-masked phase III study. Acta Ophthalmol. 2010;88:12-19.

12. Baudouin C. Side effects of antiglaucomatous drugs on the ocular surface. Curr Opin Ophthalmol. $1996 ; 7: 80-86$

13. Brasnu E, Brignole-Baudouin F, Riancho L, Guenoun JM, Warnet JM, Baudouin C. In vitro effects of preservative-free tafluprost and preserved latanoprost, travoprost, and bimatoprost in a conjunctival epithelial cell line. Curr Eye Res. 2008;33:303-312.

14. Martone, G, Frezzotti P, Tosi GM et al. An in vivo confocal microscopy analysis of effects of topical antiglaucoma therapy with preservative on corneal innervation and morphology. Am J Ophthalmol. 2009; 147:725-735.
15. Vaede D, Caudouin C, Warnet JM, et al. Preservatives in eyedrops: toward awareness of their toxicity. J Fr Ophthalmol. 2010;33:505-524.

16. Baudoin C. Mechanisms of failure in glaucoma filtering surgery: a consequence of antiglaucomatous drugs? Int J Clin Pharmacol Res. 1996;16:29-41.

17. Baudouin C, Labbé A, Liang H, Pauly A, BrignoleBaudouin F. Preservatives in eyedrops: the good, the bad and the ugly. Prog. Retin Eye Res. 2010;29:312-334.

18. Erb C, Gast U, Schremmer D. German register for glaucoma patients with dry eye. I. Basic outcome with respect to dry eye. Graefes Arch Clin Exp Ophthalmol. 2008;246:1593-601.

19. Leung EW, Kedeiros FA, Weinreb RN. Prevalence of ocular surface disease in glaucoma patients. J Glaucoma. 2008;17:350-355.

20. Rossi GC, Tinelli C, Pasinetti GM, et al. Dry eye syndrome-related quality of life in glaucoma patients. Eur J Ophthalmol. 2009;19:572-579.

21. Fechtner RD, Godfrey DG, Budenz D, et al. Prevalence of ocular surface complaints in patients with glaucoma using topical intraocular pressurelowering medications. Cornea. 2010;29:618-621.

22. Uusitalo H, Chen E, Pfeiffer N, et al. Switching from a preserved to a preservative-free prostaglandin preparation in topical glaucoma medication. Acta Ophthalmol. 2010;88:329-336.

23. Hommer A, Mohammed Ramez O, Burchert M, Kimmich F. IOP-lowering efficacy and tolerability of preservative-free tafluprost $0.0015 \%$ among patients with ocular hypertension or glaucoma. Curr Med Res Opin. 2010;26:1905-1913.

24. Kahook, MY, Noecker, R Quantitative analysis of conjunctival goblet cells after chronic application of topical drugs. Adv Ther. 2008;25:743-751.

25. Baudouin C. Detrimental effect of preservatives in eyedrops: implications for the treatment of glaucoma. Acta Ophthalmol. 2008;86:716-726. 